\title{
Development of an LC-MS/MS Method for Trace Level Quantification of 4-(bromomethyl) Benzoic Acid, a Potential Genotoxic Impurity in Imatinib Mesylate Drug Substance
}

\author{
Nelaturi Subbaiah*1, G. Jegan'², P. Suresh Babu ${ }^{3}$, J Jayachandran ${ }^{4}$, Nitesh Kanyawar ${ }^{5}$, Manish Gangrade ${ }^{6}$ \\ Analytical Research and Development, Virgonagar, Bangalore, 560049, India \\ Corresponding Author Email ID: nelaturi.subbaiah[at]cipla.com
}

\begin{abstract}
A reversed-phase selective and sensitive liquid chromatography coupled with tandem mass spectrometric (LC-MS/MS) method was developed and validated for the trace analysis of $(0.5$ ppm level) of 4-(bromomehtyl)benzoic acid genotoxic impurity in imatinib mesylate drug substance. The method obtained with Inertsil C18 column $(250 \mathrm{~mm} \times 4.6 \mathrm{~mm}, 5.0$ um) with negative electrospray ionization in multiple reaction monitoring (MRM) detection mode.Mobile phase was $0.1 \%$ formic acid in water and acetonitrile in the ratio of 35:65(v/v). Isocratic program was developed and the flow rate was $1.0 \mathrm{~mL} / \mathrm{min}$ and elution was monitored by mass spectrophotometer. The method was validated as per International Conference on Harmonization (ICH) guidelines and was able to quantitate up to 0.5ppm of 4-bromo mehtyl benzoic acid.
\end{abstract}

Keywords: Imatinib mesylate, LC-MS/MS, Genotoxic impurity, Multiple reaction monitoring (MRM)

\section{Introduction}

Imatinib Mesylate chemically Known as 4-[(4methylpiperazin-1-yl) methyl]-N-(4-methyl-3-\{[4-(pyridin3-yl) pyrimidin-2-yl] amino phenyl) benzamide, has an empirical formula of $\mathrm{C} 29 \mathrm{H} 31 \mathrm{~N} 7 \mathrm{O} . \mathrm{CH} 3 \mathrm{SO} 3 \mathrm{H}$ and a molecular weight of 589.72. Imatinib Mesylate is a tyrosinekinase inhibitor used in the treatment of multiple cancers, most notably Philadelphia chromosome-positive $(\mathrm{Ph}+)$ chronic myelogenous leukemia (CML) [1]. Like all tyrosinekinase inhibitors, Imatinib Mesylate works by preventing a tyrosine kinase enzyme, in this case BCR-Abl, from phosphorylating subsequent proteins and initiating the signaling cascade necessary for cancer development, thus preventing the growth of cancer cells and leading to their death by apoptosis [2]. The chemical structure of Imatinib mesylate and genotoxic impurity are shown in figure 1 .

Due to the advanced technical capability in identifying the potential genotoxic impurities (PGIs) and their potential impact on human health, regulatory issues related to the presence of PGIs have been arisen [3]. Starting materials, intermediates, process impurities and by-products are often found as impurities in drug substances. Some of these known impurities are potential mutagens or carcinogensand they have potential to cause cancer in human was observed by Bolt et al[4]. Muller et al [5] Jacobson and McGovern [6]. But it is difficult/impossible to eliminate them completely from the synthetic scheme. As per the guidelines from the European Medicines Agency on the limits of genotoxic impurities, a threshold of toxicological concern (TTC) value of $1.5 \mu \mathrm{g} /$ day intake of a genotoxic impurity is considered to be associated with an acceptable riskfor most of the pharmaceuticals [7,8]. Testing and control of genotoxic impurities at trace levels presents challenges to the pharmaceutical industry with regard to both analytical and process controls [9-10].
Though 4-(bromomethyl)benzoic acidis a well known carcinogen, this data would ascertain that the regulatory authoritiesmay be expected to control the level of 4(bromomethyl)benzoic acidto be $2 \mathrm{ppm}$ in the drug substance (assuming a $1.5 \mu \mathrm{g} /$ daydaily dose). A method capable of such a lower level of detection is great challenge for analytical methoddevelopment for control the genotoxic impurity. Ideally conventional analytical instruments inpharmaceutical industries such as HPLC with UV detection and GC with FID detection should be employedas the standards in first attempt for PGIs analysis and these methods were discussed by Klick [11] and Valvoet al.[12], but there are some drawbacks with above mentioned techniques because probability of co-elution atvery trace level can change analytical result. When impurity standards are not available some method isneeded to characterize the impurities on-line. Therefore, for accurate determination at ppm levels the abovementioned techniques are inadequate; consequently there is a great need to develop better analytical methodfor the analysis of such genotoxic impurities in pharmaceutical industries. As a result various kinds ofchromatographic techniques and methodologies have been explored as useful approaches out of Hsieh andKorfmacher [13] and Lee and Kems [14] had discussed LC-MS/MS technique and application. It was feltnecessary to develop slective and sensitive and validated method for estimation of 4-(bromomethyl)benzoic acid. The literature surveyrevealed that Raja et al. [15] developed and reported spectrophotometric methods for the determination ofImatinib mesylate API.

We have developed LC-MS/MS method that can quantitate at permitted limit level of impurity in Imatinib mesylate. This method to be validated as per ICH guidelines [16] in terms of limit of detection (LOD), limit of quantification (LOQ), linearity, precision, accuracy, specificity and robustness. 
<smiles>Cc1ccc(NC(=O)c2ccc(CN3CCN(C)CC3)cc2)cc1Nc1nccc(-c2cccnc2)n1</smiles>

Chemical Formula: $\mathrm{C}_{29} \mathrm{H}_{31} \mathrm{~N}_{7} \mathrm{O}$

Exact Mass: 589.25<smiles>O=C(O)c1ccc(CBr)cc1</smiles>

4-(bromomethyl)benzoic acid

\section{IMATINIB MESILATE}

Figure 1: The chemical structure of Imatinib mesylate and genotoxic impurity

\section{Experimental}

\subsection{Reagents and standards}

Formic acid and acetonitrile were obtained in their LCMS grade from Merck (Mumbai, India). Purified water collected through Milli-Q Plus water purification system (Millipore, Milford ford, MA, USA). Imatinib mesylate and 4(bromomethyl)benzoic acidwere obtained from Cipla Ltd (R\&D, Bangalore, India).

\subsection{Instrumentation}

The mass spectrometer LC-MS/MS system used was an Applied Bio system Sciex QTRAP-5500 Model(Switzerland). LC was carried out on Agilent HPLC (1200 series, Germany) with photodiode array detector. Other small equipment were PCI sonicator (22L500/CC/DTC), precision analytical balance (MX5, Mettler Toledo, Schwerzenbach, Switzerland). Data acquisition and processing were conducted using the Analyst 1.5.2 software on a dell computer (Digital equipment Co).

\subsection{Chromatographic conditions}

All chromatographic experiments were carried out onAgilent HPLC (1200 series, Germany) with photodiode array detector system coupled with MS/MS (Applied Bio system Sciex QTRAP-5500 model, Rotkreuz, Switzerland). The analytical column used was Inertsil ODS 3V column (250 $\mathrm{mm}$ x $4.6 \mathrm{~mm}$ i.d., particle size $5 \mu \mathrm{m}$ ) procured from LCGC (Bangalore, INDIA). The mobile phase flow operated in isocratic mode using $0.1 \%$ formic acid in water and acetonitrile in the ratio of $35: 65(\mathrm{v} / \mathrm{v})$. The flow rate was 1.0 $\mathrm{mL} / \mathrm{min}$, with the flow rate split down to $0.4 \mathrm{~mL} / \mathrm{min}$ in to the MS source. The column oven temperature was maintained at $40^{\circ} \mathrm{C}$, sample cooler temperature was $15^{\circ} \mathrm{C}$. The injection volume was $20 \mu \mathrm{L}$.Negative ion electrospray ionization probe was operated withmultiple reaction monitoring (MRM) detection mode. Electrospray ionisation in negative mode was used with MRM monitoring for $\mathrm{m} / \mathrm{z}$ 213.0>78.9 transition for 4-(bromomethyl)benzoic acid and $494.2>394.3$ transition for Imatinib. The Declustering potential $(\mathrm{V})$, entrance potential $(\mathrm{V})$, Collision energy $(\mathrm{V})$, Collision exit potential $(\mathrm{V})$ and ion spray voltage $(\mathrm{V})$ were kept as $-40,-10,-21,-12$ and 5500 , respectively. The source temperature $\left({ }^{\circ} \mathrm{c}\right)$, curtain gas flow (psi), ion source gas1 and ion source gas 2 were maintained as $400,40,45$ and 45 , respectively.

\subsection{Standard and sample preparation}

The diluent used as water and acetonitrile in the ratio of 50:50 (v/v). $0.1 \mathrm{mg} / \mathrm{mL}$ reference stock solution was prepared by dissolving 4-(bromomethyl)benzoic acidin diluent, Preparation of sub stock standard solution of 0.001 $\mathrm{mg} / \mathrm{mL}$ was achieved on further dilution with diluent. Finally desired concentration $(2 \mathrm{ng} / \mathrm{mL})$ of standard solution was prepared by diluting standard sub stock solution to 100 $\mathrm{mL}$ with diluent. Linearity solution prepared from further dilution of standard solution of $0.5,1,1.5,2,4$ and 6 $\mathrm{ppm}$.The testing API sample was typicallyprepared at approximately $1 \mathrm{mg} / \mathrm{mL}$ with diluent.

\section{Results and Discussion}

\subsection{Method development}

The main objective of method development was to achieve efficient separation between Imatinib mesylateand 4(bromomethyl)benzoic acid. Different stationary phases have been assessed which included C18, C8 and amino phases. In addition different mobile phase additives such as formic acid, ammonium acetate, acetonitrile and methanol have been tested. Chromatographic separation was finally achieved on Inertsil ODS $3 \mathrm{~V}(250 \mathrm{~mm} \times 4.6 \mathrm{~mm}) 5 \mu \mathrm{m}$ column(LCGC Co, India) in isocratic mode using $0.1 \%$ formic acid in water and acetonitrile in the ratio 35:65(v/v). The flow rate was $1.0 \mathrm{~mL} / \mathrm{min}$, with the flow rate split down to $0.4 \mathrm{~mL} / \mathrm{min}$ in to the MS source andmass spectrometer parameter set to get maximum sensitivity for 4(bromomethyl)benzoic acid. 


\section{International Journal of Science and Research (IJSR)}

ISSN (Online): 2319-7064

Index Copernicus Value (2015): 78.96 | Impact Factor (2015): 6.391

\subsection{Method validation}

\subsubsection{Specificity}

The specificity of the method was checked by injecting 1.0 ppm of Imatinib mesylate and 4-(bromomethyl)benzoic acidwith respect to the test concentration, the retention times shown in table 1. Blank and Specificity chromatograms are shownin the figure 2 to 4 .

Table 1: Determination of specificity

\begin{tabular}{|c|c|c|}
\hline S. No. & Name & Retention time (min) \\
\hline 1 & Imatinib & 1.13 \\
2 & 4-(bromomethyl)benzoic acid & 2.51 \\
\hline
\end{tabular}

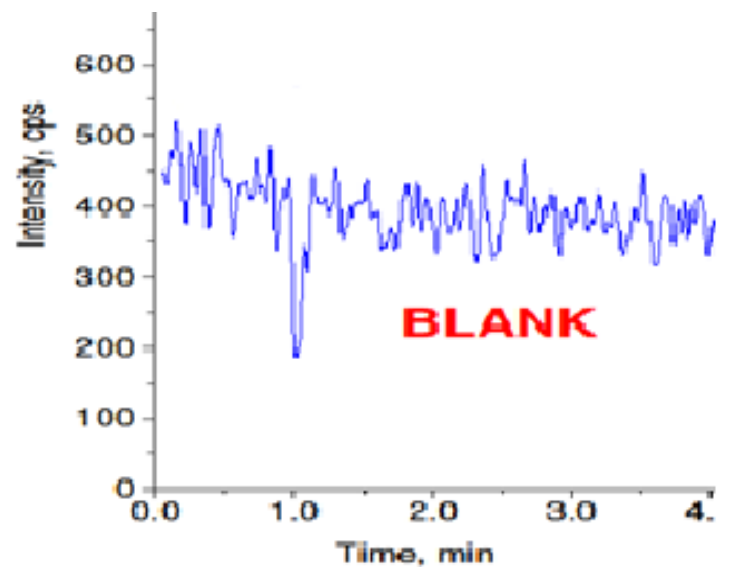

Figure 2: Blank chromatogram for specificity

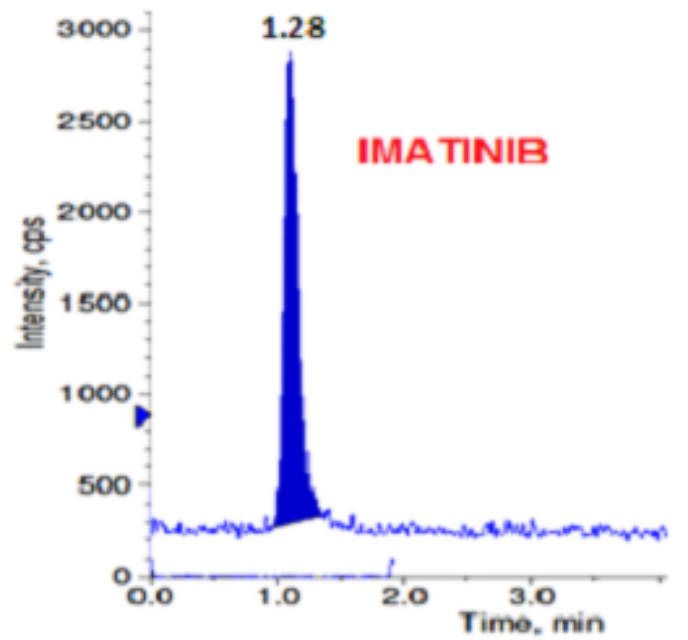

Figure 3: Imatinib chromatogram for specificity

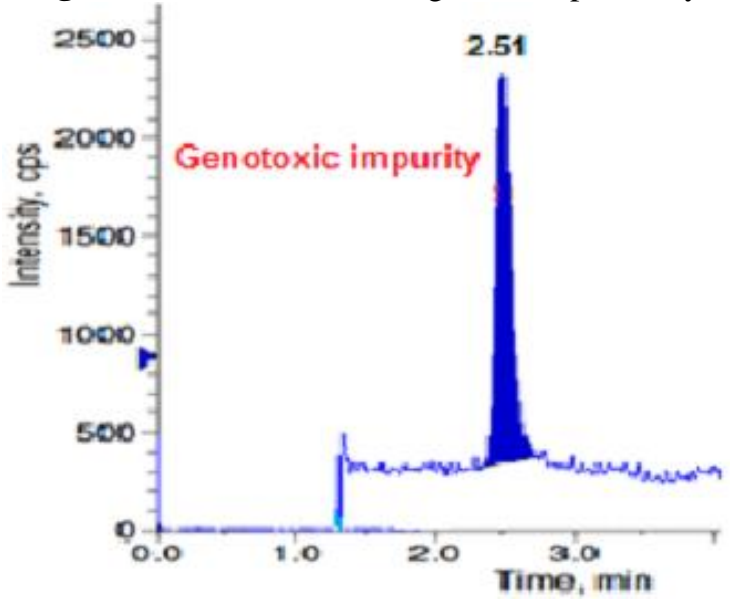

Figure 4: 4-(bromomethyl)benzoic acidchromatogram for specificity

\subsubsection{Determination of LOD and LOQ}

The LOD and LOQ were calculated from S/N (signal to noise) ratio. Now to determine LOD andLOQ values of 4 (bromomethyl)benzoic acidconcentrationwere reduced sequentially such that they yield $\mathrm{S} / \mathrm{N}$ ratio as 4.9 and 11.6 respectively. The LOQ of $0.5 \mathrm{ppm}$ is typical for the 4 (bromomethyl)benzoic acid, with LOD approximately three times less than LOQ.

\subsubsection{Linearity}

Linearity of the method was checked by preparing solutions at six concentration levels of $0.5 \mathrm{ppm}$ (LOQ), $1 \mathrm{ppm}$ (L1 solution), $1.5 \mathrm{ppm}$ (L2 solution), 2ppm (L3 solution), 4ppm (L4 solution) and 6ppm (L5 solution) for 4(bromomethyl)benzoic acid. LOQ solution and L5 solution were injected six times and L1, L2,L3 and L4 solution were injected two times. The mean responses recorded for each impurity were plottedagainst concentration. The correlation coefficient was found to be 0.9996 and shown in figure 5 .

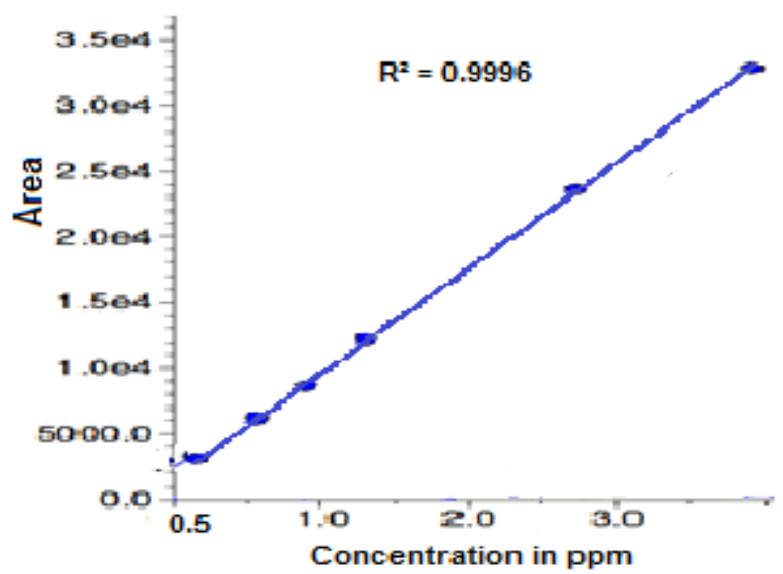

Figure 5: Linearity graph of 4-(bromomethyl)benzoic acid

\subsubsection{Recovery}

Hence the recovery studies by the standard addition method were performed to evaluate accuracy and specificity, accordingly the accuracy of the method was determined in six replicate at LOQ level and remaining level (level 1, 2, 3, 4 and level 5) triplicate in bulk drug sample. Then the percentage recoveries were calculated. Excellent recovery values of 4-(bromomethyl) benzoic acid(88-107\%)was obtained.

\subsubsection{System, method and intermediate precision}

Infact 4-(bromomethyl)benzoic acidin imatinib mesylate was checked for repeatability. The standard solution was prepared 2ppm (limit level) with respect to test concentration and injected six times for system precision. The $\%$ RSD was found to be less than $10.0 \%$. To determine the method precision six independent solutions were prepared by spiking Imatinib mesylate with the impurity at a concentration of $2 \mathrm{ppm}$ with respect to target analyte concentration.Intermediate precision was studied with different column, different instrument and different day. $\%$ RSD of all the above determinations were calculated and found below 15 . 


\section{International Journal of Science and Research (IJSR) \\ ISSN (Online): 2319-7064}

Index Copernicus Value (2015): 78.96 | Impact Factor (2015): 6.391

\subsubsection{Robustness}

Robustness of the method was determined by making slight and deliberate changes in experimentalconditions. The flow rate of mobile phase was altered by 0.1 units i.e. 1.0 to 1.1 $\mathrm{mL} / \mathrm{min}, 1.0$ to 0.9 and effectof temperature on resolution was also studied at $38^{\circ} \mathrm{C}$ and $42^{\circ} \mathrm{C}$ (altered by 2 units). The cumulative \% RSD values from method precision and robustness study (altered conditions) were calculated. The $\%$ RSD values calculated were found to be below 15 for 4 (bromomethyl)benzoic aciddemonstrate that the method was robust.

\subsubsection{Stability of analytical solution}

Sample solution was prepared as per the proposed method. The 4-(bromomethyl)benzoic acidwas quantitatively spiked at limit level concentrationand stored at $15^{\circ} \mathrm{C}$. The spiked sample was injected into the system initially and at various time intervals. The \% variation of 4-(bromomethyl)benzoic acidin the initial and each interval was calculated and found to be below 10. This indicates that the sample solution was found to be stable up to 22 hours at $15^{\circ} \mathrm{C}$.

\section{Conclusion}

The results of the present study indicated that the newly developed LC-MS/MS method is simple, cost-effective, linear, accurate, precise and robust over the specified range and selective for the quantification of 4(bromomethyl)benzoic acidin IMT-03 (intermediate) and Imatinib mesylate drug substance at low concentration levels. The LOD and LOQ of the developed method were quite satisfactory. In addition to this method can be reliably and successfully for the estimation of 4(bromomethyl)benzoic acidfor routine quality control and stability studies.

\section{Acknowledgements}

The authors wish to thank the management of Cipla Ltd,for their support encouragement and permitting this work to communication for publication. Alsoauthours would like to express their special thanks to Mr. PLS as well as who supported throughout this study.

\section{References}

[1] Novartis Pharma AG. Gleevec ${ }^{\circledR}$ (Imatinib mesylate) tablets prescribing information. EastHanover, NJ; Anon. Drugs of choice for cancer. Treat Guidel Med Lett. Sep 2006.

[2] J.M. Goldman, F.R.C.P., J. V. Melo, "Chronic myeloid leukemia - advances in biology and newapproaches to treatment",N Engl J Med, 349, pp. 1451-1464, 2003.

[3] International Conference on Harmonisation of Technical Requirements for Registration of Pharmaceuticals for Human Use, S2 (R1), 2011.

[4] H.M. bolt, H. Foth, J.G. Hengstler, G.H. Degan, "Carcinogenicity categorization of chemicals-new aspects to be considered in a European perspective", Toxicology Letters, 151, pp. 29-41, 2004.

[5] L. Muller, R.J. Mauthe, C.M. Riley, M.M. Andino, D. De Antonis, C. Beels, J. DeGeorge, A.G.M. De Knaep,
D. Ellison, J.A. Fagerland, R. Frank, B. Fritschel, S. Galloway, E. Harpur, C.D.N. Humfrey, A.S. Jacks, N. Jagota, J. Mackinnon, G. Mohan, D.K. Ness, M.R. O' Donovan, M.D. Smith, G. Vudathala, L. Yotti, "A rationale for determining testing, and controlling in specific impurities in pharmaceuticals that possess potential for genotoxicity", Reg. Toxicol. Pharmacology, 44, pp. 198-211, 2006.

[6] D. Jacobson-Kram, T. McGovern, "Toxicological overview of impurities in pharmaceutical products", Adv. Drug deliv. Reviews, 59, pp. 38-42, 2007.

[7] Guideline on the limits of genotoxic impurities, EMA guidance MEA/CHMP/QWP/251344/2006.

[8] Guideline for Assessment and Control of DNA Reactive (Mutagenic) Impurities in pharmaceuticals to Limit Potential Carcinogenic risk, M7 ICH, 2014.

[9] E.J. Delaney, "An impact analysis of the application of the threshold of toxicological concern concept to pharmaceuticals", Reg. Toxicol. Pharmacology, 49, pp. 107-124, 2007.

[10] McGovern T, Jacobson-Kram D, "Trends in Analytical Chemistry", 25, pp. 790-795, 2006.

[11] S. Klick, "Evaluation of different injection techniques in the gas chromatographic determination of thermolabile trace impurities in a drug substance", J. Pharm. Biomed. Analysis, 13, pp. 563-566, 1995.

[12] L. Valvo, R. Alimenti, S. Alimonti, S. Raimondi, F. Foglietta, F. Campana, "Development and validation of a liquid chromatographic method for the determination of related substances in verapamil hydrochloride", J. Pharm. Biomed. Analysis, 15, pp., 989-996, 1997.

[13] Y. Hsieh, W.A. Korfmacher, "Increasing speed and Throughput when using HPLC-MS/MS systems for Drug Metabolism and pharmacokinetic Screening", Curr. Drug Metabolism, 7, pp. 479-489, 2006.

[14] M.S. Lee and E.H. Kerns, "Mass spectrometry reviews", 18, pp. 187-279, 1999.

[15] J. Kumar Raja, V. D. Sundar, A. R Magesh, S. Nandha Kumar and M. D. Dhanaraju, "Validated spectrometric estimation of Imatinib mesylate in pure and tablet dosage form", IJPT, 2(3), pp.490-495 2010.

[16] Guidelines for Validation of Analytical Procedures, Q2 (R1), ICH, 1994. 